\title{
Effect of the Side Chains and Anode Material on Thermal Stability and Performance of Bulk-Heterojunction Solar Cells Using DPP(TBFu $)_{2}$ Derivatives as Donor Materials
}

\author{
Alexander Kovalenko, ${ }^{1}$ Jana Honová, ${ }^{1}$ Martin Vala, ${ }^{1}$ Stanislav Luňák, ${ }^{1}$ Ladislav Fekete, \\ Petra Horáková, ${ }^{3}$ Lenka Dokládalová, ${ }^{3}$ Lubomír Kubáč, ${ }^{3}$ and Martin Weiter ${ }^{1}$ \\ ${ }^{1}$ Faculty of Chemistry, Materials Research Centre, Brno University of Technology, Purkyňova 118, 61200 Brno, Czech Republic \\ ${ }^{2}$ Institute of Physics, Academy of Sciences Czech Republic v.v.i, Na Slovance 2, 18221 Prague 8, Czech Republic \\ ${ }^{3}$ Centre for Organic Chemistry Ltd., Rybitví 296, 53354 Rybitví, Czech Republic \\ Correspondence should be addressed to Alexander Kovalenko; kovalenko.alx@gmail.com
}

Received 17 September 2015; Accepted 8 December 2015

Academic Editor: Jegadesan Subbiah

Copyright (c) 2015 Alexander Kovalenko et al. This is an open access article distributed under the Creative Commons Attribution License, which permits unrestricted use, distribution, and reproduction in any medium, provided the original work is properly cited.

\begin{abstract}
An optimized fabrication of bulk-heterojunction solar cells (BHJ SCs) based on previously reported diketopyrrolopyrrole donor, ethyl-hexylated $\mathrm{DPP}(\mathrm{TBFu})_{2}$, as well as two new $\mathrm{DPP}(\mathrm{TBFu})_{2}$ derivatives with ethyl-hexyl acetate and diethyl acetal solubilizing side-chains and $\mathrm{PC}_{60} \mathrm{BM}$ as an acceptor is demonstrated. Slow gradual annealing of the solar cell causing the effective donoracceptor reorganization, and as a result higher power conversion efficiency (PCE), is described. By replacing a hole transporting layer PEDOT:PSS with $\mathrm{MoO}_{3}$ we obtained higher PCE values as well as higher thermal stability of the anode contact interface. $\mathrm{DPP}(\mathrm{TBFu})_{2}$ derivative containing ethyl-hexyl acetate solubilizing side-chains possessed the best as-cast self-assembly and high crystallinity. However, the presence of ethyl-hexyl acetate and diethyl acetal electrophilic side-chains stabilizes HOMO energy of isolated $\mathrm{DPP}(\mathrm{TBFu})_{2}$ donors with respect to the ethyl-hexylated one, according to cyclic voltammetry.
\end{abstract}

\section{Introduction}

Currently polymer and small molecules (SMs) bulkheterojunction (BHJ) organic solar cells (SCs) exceeding $11 \%$ power conversion efficiency (PCE) [1] and lifetimes above 1000 hours under continuous illumination [2,3] attracted particular interest due to their flexibility, color tunability, and predominantly potentially low production cost. Considering SMs as a donor material, despite the recent successful results $[4,5]$, they still lag behind the polymer BHJ solar cells. However small-molecules BHJ SCs do not depend on a polymer weight distribution; thus they do not suffer from batch-tobatch differences [6]. One of the most promising structural classes of the donors in $\mathrm{BHJ}$ SCs is diketopyrrolopyrrole (DPP) derivatives, which show excellent photovoltaic performance as both a part of polymers [7-10] and dimers [11-13], because of a low band gap, enabling them to absorb a large portion of the solar spectrum, as well as an ability to be further functionalized to match the parameters required for the photovoltaic applications. Among the DPP monomers, $\mathrm{DPP}(\mathrm{TBFu})_{2}$ ethyl-hexyl alkylated derivative (compound (A) on Figure 1) showing high power-conversion efficiency (PCE) up to $4.4-4.8 \%$ with $\mathrm{PC}_{70} \mathrm{BM}[14,15]$ and $4.0 \%$ with $\mathrm{PC}_{60} \mathrm{BM}$ [16] represents the most successful design. Applying a solvent annealing for the $\mathrm{DPP}(\mathrm{TBFu})_{2}: \mathrm{PC}_{70} \mathrm{BM}$ blend $5 \%$ of PCE can be exceeded [17], which is, up to now, the highest reported PCE among the monomeric DPP derivatives. Consequently, relatively easily (as compared to, e.g., bis-DPPs) obtainable $\mathrm{DPP}(\mathrm{TBFu})_{2}$ is often used as a benchmark compound in the current research dealing with new SM donors [18-20], acceptors [21], or tandem cells [22]. The attempts to modify $\mathrm{DPP}(\mathrm{TBFu})_{2}$ structure using different heteroatoms brought only lower PCE $[15,20]$. DPP $(\mathrm{TBFu})_{2}$ belongs to SM donors, for which the relationships between the structure $[15,23,24]$ and various aspects of the photovoltaic activity such as hole mobility [25] were understood to the most detailed extent. 


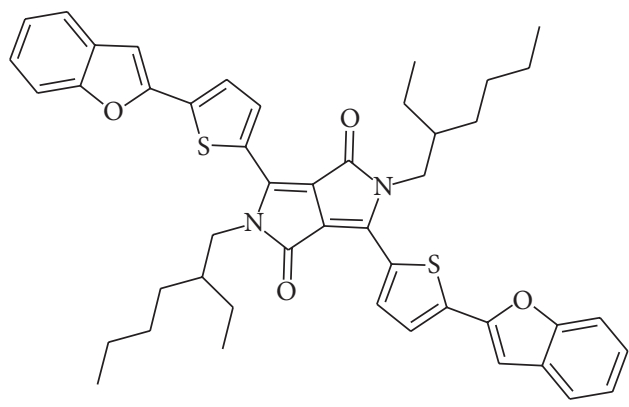

(A)

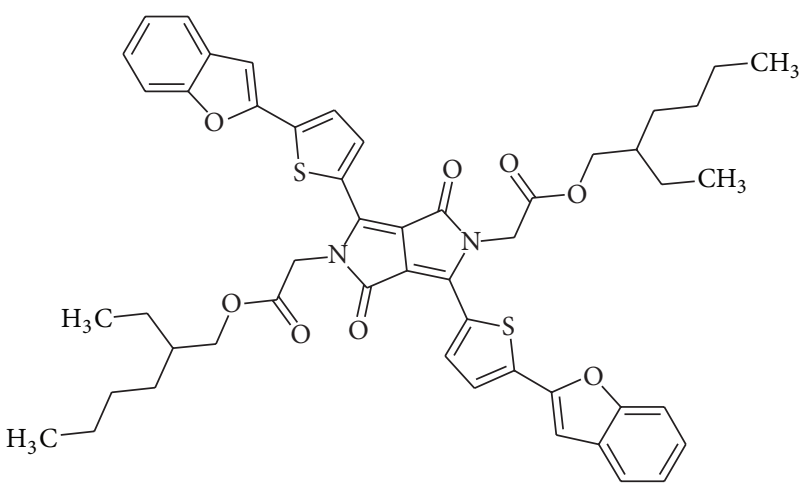

(B)

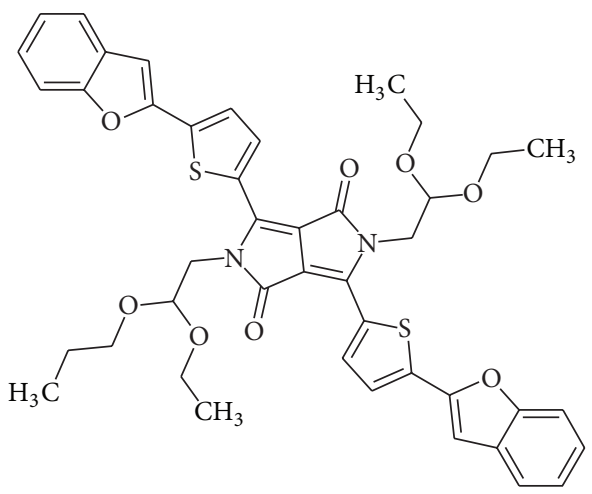

(C)

FIGURE 1: DPP(TBFu $)_{2}$ derivatives substituted with ethyl-hexyl (A), ethyl-hexyl acetate (B), and diethyl acetal (C) solubilization groups.

PCE of BHJ SCs using $\mathrm{DPP}(\mathrm{TBFu})_{2}$ as a donor is known to be extremely sensitive to annealing at (constant) temperature [14]. Furthermore, to the best of our knowledge, PEDOT:PSS is the only hole-selective (transporting) contact (HSC) reported in the previous studies. Here we report a new method of the gradual annealing, causing the progressive reorganization of the donor-acceptor bulk-heterojunction, improving the solar cells performance. It is known that the $\mathrm{MoO}_{3}$ used as HSC $[26,27]$ instead of PEDOT:PSS can improve in some cases PCE of BHJ SCs [28], so we studied its effect in detail, including the thermal stability of the contacts. Moreover, we have tested the new $\operatorname{DPP}(\mathrm{TBFu})_{2}$ derivatives with ethyl-hexyl solubilization groups substituted by ethylhexyl acetate [19] and diethyl acetal [29] groups (Figure 1 compounds (B) and (C)). It was expected that the electronaccepting effect of these substituents could stabilize HOMO level [30] of a donor and thus improve the open-circuit voltage of the cell.

\section{Experimental}

2.1. Materials. The synthesis and analysis of DPP donors (A)-

(C) are described in Supporting Info (SI).

$\mathrm{PC}_{60} \mathrm{BM}$ (Solenne, 99\%), chloroform (Aldrich, 99.9\%), $\mathrm{MoO}_{3}$ (Aldrich, 99.98\%), and Al (Aldrich, 99.99\%) were used as received without further purification. Prior to dissolving, materials for the active layer were kept in vacuum at $60^{\circ} \mathrm{C}$ overnight and then transferred to the nitrogen atmosphere. The solution for the active layer films was prepared from a DPP:PC ${ }_{60} \mathrm{BM}$ blend $\left(1.5: 1\right.$ by weight for all $\mathrm{DPP}(\mathrm{TBFU})_{2}$ derivatives) in chloroform with a total concentration of $20 \mathrm{mg} / \mathrm{mL}$ following the sonication for 5 minutes until complete DPP dissolution. All manipulations were carried out in a glovebox under a nitrogen atmosphere unless otherwise stated.

2.2. Device Fabrication. For the regular device architecture glass substrates with patterned ITO were covered by PEDOT:PSS by spin coating at $5500 \mathrm{rpm}$ for 60 seconds with consequent annealing for 10 minutes at $150^{\circ} \mathrm{C}$ in the air and then annealed in the inert nitrogen atmosphere for another 10 minutes at $150^{\circ} \mathrm{C}$ to remove residual moisture. As an alternative hole-selective contact $10 \mathrm{~nm}$ thick $\mathrm{MoO}_{3}$ layers were thermally evaporated in the vacuum chamber on the pixelated glass/ITO substrates. $\mathrm{DPP}(\mathrm{TBFu})_{2}: \mathrm{PC}_{60} \mathrm{BM}$ heterojunction layer was created by dynamic spin coating of $25 \mu \mathrm{L}$ of prepared solution at $2500 \mathrm{rpm}$ for 40 seconds in nitrogen atmosphere. Thickness of all the layers measured by the profilometer was in a range of $100 \mathrm{~nm}$. Consequently gradient thermal annealing was applied in the glovebox starting from $50^{\circ} \mathrm{C}$ and speed $1^{\circ} \mathrm{C} /$ minute up to the notable degradation of the cell. After every 10 degrees efficiencies 
TABLE 1: The first half-wave $\left(E_{1 / 2}\right)$ oxidation $(\mathrm{Ox} 1)$ and reduction (Red1) potentials obtained from rotating disk voltammetry recomputed [31] to frontier orbital energy levels. Absorption maxima $\lambda_{\mathrm{MAX}}$ of $0-0$ and $0-1$ vibronic subbands of the longest wavelength band (absolute maxima are in bold and relate to molar absorptivities $\varepsilon$ ).

\begin{tabular}{lccccccc}
\hline Compound & $E_{1 / 2}(\mathrm{oxl})[\mathrm{V}]$ & $E_{1 / 2}(\mathrm{red} 1)[\mathrm{V}]$ & $E_{\mathrm{HOMO}}[\mathrm{eV}]^{\mathrm{a}}$ & $E_{\mathrm{LUMO}}[\mathrm{eV}]^{\mathrm{b}}$ & $E_{\mathrm{HL}}[\mathrm{eV}]^{\mathrm{c}}$ & $\lambda_{\mathrm{MAX}}[\mathrm{nm}]$ & $\varepsilon[\mathrm{L} / \mathrm{mol} \cdot \mathrm{cm}]$ \\
\hline A & 0.91 & -0.88 & -5.26 & -3.47 & 1.79 & $\mathbf{6 2 8}, 584$ \\
$\mathrm{~B}$ & 1.01 & -0.86 & -5.36 & -3.49 & 1.87 & $\mathbf{6 2 2}, 578$ \\
$\mathrm{C}$ & 0.95 & -0.88 & -5.30 & -3.47 & 1.83 & $614, \mathbf{5 7 8}$ & 60383 \\
\hline
\end{tabular}

${ }^{\mathrm{a}} E_{\mathrm{HOMO}}[\mathrm{eV}]=E_{1 / 2}(\mathrm{oxl})[\mathrm{V}]+4.35[32]$.

${ }^{\mathrm{b}} E_{\mathrm{LUMO}}[\mathrm{eV}]=E_{1 / 2}(\mathrm{red} 1)[\mathrm{V}]+4.35[32]$.

${ }^{\mathrm{c}} E_{\mathrm{HL}}[\mathrm{eV}]=E_{\mathrm{HOMO}}-E_{\mathrm{LUMO}}=$ electrochemical HOMO - LUMO gap.

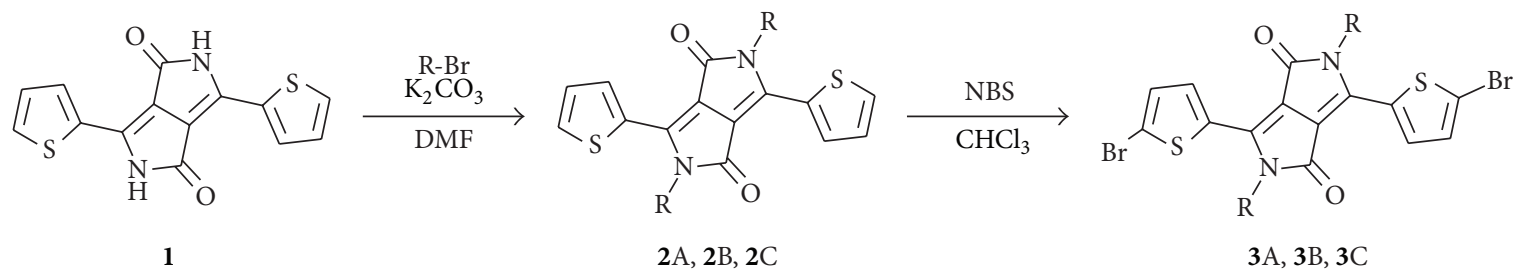<smiles>[R]CC(CC)CCCC</smiles>

FIGURE 2: Reaction scheme.

of the solar cells were measured in ambient atmosphere at room temperature. Al top electrode was deposited by thermal vacuum deposition; active area mask was $6 \mathrm{~mm}^{2}$.

2.3. Solar Cell Characterization Techniques. Current densityvoltage measurements were carried out under illumination using an Abet Sun 2000 solar simulator with an air mass (AM) $1.5 \mathrm{G}$ filter. The simulated light intensity was adjusted to $1000 \mathrm{Wm}^{-2}$ by using a NREL-calibrated Si solar cell.

\section{Results and Discussion}

3.1. Synthesis and Molecular Properties. All three DPP derivatives $(\mathrm{A})-(\mathrm{C})$ were synthesized according to scheme in Figure 2. While the yields of the bromination and crosscoupling reactions always exceeded $80 \%$ and $70 \%$, respectively, the alkylation reactions proved to be more problematic. Alkylation of moderately soluble substrate 1 with 1-bromo2-ethylhexane (or bromoacetaldehyde diethyl acetal) yielded half amount of the desired product compared to that obtained when 2-ethylhexyl 2-bromoacetate was used. This is mainly caused by a competitive $O$-alkylation [33] in the former case, which was not observed in the latter one by TLC, as in previous studies [29, 32]. Furthermore, the latter reaction was finished at considerably shorter reaction time. Slight modification of the original Suzuki-Miyaura cross-coupling reaction [14] utilizing benzofuran pinacolate 4 instead of the corresponding boronic acid and $\mathrm{PdCl}_{2}\left(\mathrm{PPh}_{3}\right)_{2}$ instead of $\mathrm{Pd}_{2}(\mathrm{dba})_{2}$ catalyst increased the yield of the last step from 67 to $81 \%$ for $(\mathrm{A})$.

Spectral and electrochemical data are summarized in Table 1 and the absorption spectra in DCM are shown in Figure S1 (in Supplementary Material available online at http://dx.doi.org/10.1155/2015/734917). It is quite interesting that the HOMO and the LUMO levels of (A), derived from two electrochemical ionization reactions in solution $(-5.26 \mathrm{eV}$ and $-3.47 \mathrm{eV})$, are only about $0.06-0.07 \mathrm{eV}$ lower than the values recorded in the solid-state. The latter values were derived from a combination of the ionization reaction, estimated by photoelectron spectroscopy, and the absorption onset $(-5.20 \mathrm{eV}$ and $-3.40 \mathrm{eV})[12,14]$. These two measurements gave almost identical gaps $(1.79 \mathrm{eV}$ versus $1.80 \mathrm{eV})$. On assumption of a similar solid-state arrangement of (A) and (B), the decrease of the HOMO from $-5.26 \mathrm{eV}$ to $-5.36 \mathrm{eV}$ should lead to an increase of the open-circuit voltage of $\mathrm{BHJ}$ 
TABLE 2: Main parameters of the fabricated solar cells.

\begin{tabular}{|c|c|c|c|c|c|c|}
\hline Donor material & Anode contact & Optimum annealing $T,{ }^{\circ} \mathrm{C}$ & PCE, \% & $V_{\mathrm{oc}}, \mathrm{mV}$ & $J_{\mathrm{sc}}, \mathrm{mA} / \mathrm{cm}^{2}$ & $\mathrm{FF}, \%$ \\
\hline (A) & PEDOT:PSS & 110 & 3.75 & 865 & 9.39 & 46 \\
\hline (A) & $\mathrm{MoO}_{3}$ & 130 & 4.52 & 911 & 10.06 & 49 \\
\hline (B) & PEDOT:PSS & $100^{*}$ & 2.04 & 823 & 5.11 & 48 \\
\hline (B) & $\mathrm{MoO}_{3}$ & 140 & 3.29 & 856 & 7.90 & 49 \\
\hline (C) & PEDOT:PSS & 110 & 1.49 & 550 & 6.57 & 41 \\
\hline (C) & $\mathrm{MoO}_{3}$ & 140 & 2.28 & 797 & 6.59 & 44 \\
\hline
\end{tabular}

${ }^{*} 100^{\circ} \mathrm{C}$ in case of constant temperature and up to $160^{\circ} \mathrm{C}$ in case of gradual annealing (PCE $>2.50 \%$ ).

SC by about $0.1 \mathrm{eV}$ as the $V_{\text {oc }}$ depends primarily on the energy difference between the HOMO of the SM donor and the LUMO of the (fullerene) acceptor [34].

\subsection{Gradient Annealing Effect and Anode Contact Thermal} Stability. Firstly, the solar cells containing ethyl-hexyl alkylated sample $(\mathrm{A})$ were fabricated using standard procedure reported in [14] with donor/acceptor ratio $60: 40$ and dynamically spin-coated at $2500 \mathrm{rpm}$ for 60 seconds. PEDOT:PSS was used as an anode hole-selective contact and $\mathrm{Al}$ as a top cathode. Annealing at $110^{\circ} \mathrm{C}$ for 10 minutes was applied prior to $\mathrm{Al}$ deposition. After annealing PCE of the devices was in a range of $3.6 \pm 0.2 \%$, which is comparable with previously published results $[15,20]$ when $\mathrm{PC}_{60} \mathrm{BM}$ was used as an acceptor. Fabrication of the BHJ SCs based on the samples (B) and (C) was optimized using various donor/acceptor concentrations $(50: 50,60: 40$, and $70: 30)$ and spin coating conditions; however similarities of the donor structures lead to the same preparation conditions as for the reference (A) sample. For the above mentioned series of devices annealing at $110^{\circ} \mathrm{C}$ for 10 minutes was applied. Best PCE of the SCs based on the materials (B) and (C) was obtained as $2.04 \%$ and $1.49 \%$, respectively (Table 2 ), that is, lower than for (A) sample. Main losses were observed in the $V_{\mathrm{oc}}$ and especially in $J_{\mathrm{sc}}$.

As an alternative anode material $\mathrm{MoO}_{3}$ was used. Annealing of the devices for 10 minutes at constant temperature $110^{\circ} \mathrm{C}$ possessed similar PCE values in comparison with the devices with PEDOT:PSS. However using gradual increase of the annealing temperature it was discovered that above mentioned solar cells can not only sustain higher temperatures but also possess higher PCE values when temperatures up to $140^{\circ} \mathrm{C}$ were applied (Figure 3 ). On the contrary, for the PEDOT:PSS based devices annealing temperatures higher than $110^{\circ} \mathrm{C}$ resulted in the PCE decrease when direct annealing is applied (Figure S2), which relates to the previously reported results [14]. Gradient annealing for PEDOT:PSS based devices possesses better thermal stability at higher temperatures. In the case of compound (A) maximum efficiency reached at $80^{\circ} \mathrm{C}$ was preserved till $150^{\circ} \mathrm{C}$ with consequent degradation at higher temperatures. Devices based on compound (B) and PEDOT:PSS anode have shown the best thermal stability among all the PEDOT:PSS based devices; maximum efficiency was reached at $160^{\circ} \mathrm{C}$ with consequent degradation.

Interestingly, for the materials (A) and (C) during the gradient annealing maximum short-circuit current was achieved at the temperature above $100^{\circ} \mathrm{C}$; further PCE augmentation was determined by the $V_{\mathrm{oc}}$ and FF increase; notably the highest $V_{\mathrm{oc}}(954 \mathrm{mV})$ for the material (A) was measured prior to annealing; however after $V_{\text {oc }}$ decrease up to $100^{\circ} \mathrm{C}$ one can observe its slight augmentation up to $911 \mathrm{mV}$, which is even exceeding maximum $V_{\text {oc }}$ previously reported using $\mathrm{PC}_{70} \mathrm{BM}$. In the case of donor (C) gradual $V_{\text {oc }}$ augmentation is observed through the whole annealing process; however at temperatures above $140^{\circ} \mathrm{C}$ solar cells based on material (C) degraded rapidly. $V_{\text {oc }}$ increase at the constant short-circuit current can be associated with the reorganization of the donoracceptor stacking in the bulk heterojunction. In case of the material (B) maximum current can be observed even without annealing procedure, and no significant improvement in the $V_{\text {oc }}$ was observed. In case of compound (C) the highest $V_{\text {oc }}(800 \mathrm{mV})$ was observed at $150^{\circ} \mathrm{C}\left(752 \mathrm{mV}\right.$ at $\left.110^{\circ} \mathrm{C}\right)$, in case of $\mathrm{MoO}_{3}$ anode; however in case of PEDOT:PSS the highest $V_{\text {oc }}$ is observed prior to annealing $(\sim 700 \mathrm{mV})$, with a decrease to $550 \mathrm{mV}$ at $110^{\circ} \mathrm{C}$ and $400 \mathrm{mV}$ at higher temperatures (Figure S3). Thus we assume that the anode interface is not thermally stable in case of compound $(C)$ and PEDOT:PSS. In fact, among all the considered materials sample (B) showed the highest PCE at nonannealed samples (Figure 2(A)). Increase of the PCE during the annealing is observed due to the FF increase, which is influenced by the series resistance decrease. This observation can be related to the changes in contact/BHJ interface population during the annealing process. The substitution of widely used ethylhexyl with ethyl-hexyl acetate solubilization groups thus enables a formation of an appropriate bulk-heterojunction without the thermal annealing. Irrespective to the lower PCE, such behavior can be favorable if thermally unstable materials are used in a fabrication of SCs. This fact, together with above mentioned better reaction yields, makes the ethylhexyl acetate side-chain promising for further studies.

Analyzing the results of the above described gradient annealing process, we can observe that for the considered materials optimum annealing temperature lies between 130 and $140^{\circ} \mathrm{C}$ (Table 2), when $\mathrm{MoO}_{3}$ is used as a hole-selective electrode. As it has been already mentioned devices were degrading, when PEDOT:PSS layer was used instead of $\mathrm{MoO}_{3}$. As far as PEDOT:PSS is known to be stable even at higher temperatures $[35,36]$, we associate this phenomenon with the donor-acceptor morphology and PEDOT:PSS/ $\mathrm{DPP}(\mathrm{TBFu})_{2}$ interface degradation, which can be circumstantially identified by slight increase of the series 

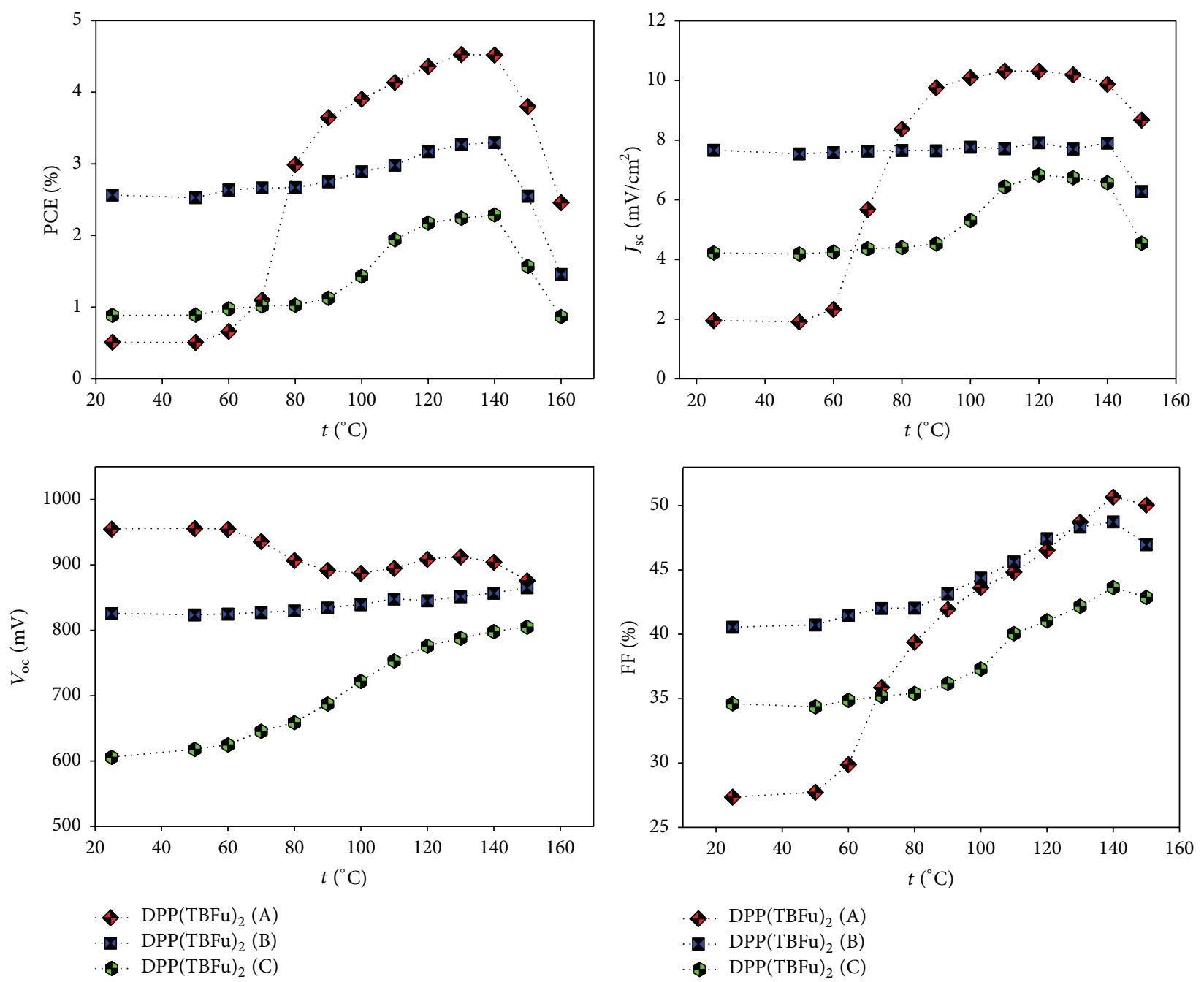

FIGURE 3: Main photovoltaic parameters of the gradually annealing of the devices with $\mathrm{MoO}_{3}$ anode layer.

resistance when samples were annealed at temperatures above $110^{\circ} \mathrm{C}$.

AFM images depicted in Figure 4 (material (A)) and Figure S3 (material (B)) clearly show the changes in the crystallinity during the annealing in case of material $\mathrm{A}$. The rms roughness has decreased from $2.6 \mathrm{~nm}$ to $0.9 \mathrm{~nm}$. Larger crystalline size is observed when the layer was annealed at $140^{\circ} \mathrm{C}$ (rms roughness $1.5 \mathrm{~nm}$ ); however at $160^{\circ} \mathrm{C}$ notable degradation of the morphology can be noticed; at the same time rms roughness has increased to $3.6 \mathrm{~nm}$. In case of the material (B) high crystallinity is observed even at nonannealed samples and significant changes in the layer morphology during the annealing were not observed.

An evolution of the solid-state absorption spectra upon annealing (Figure 5) shows the trends corresponding to the ones detected through morphology changes. In accordance with previous results for (A) [14], the 0-0 vibronic band of a solid-state absorption dramatically decreases due to annealing and the vibronic structure becomes sharper. The former effect relates to the change of an excitonic coupling from joint $\mathrm{J}$ - and $\mathrm{H}$-aggregation [37] to dominant H-type
[38], while the latter one implies the better ordered solid-state structure [39]. In the case of DPP generally [40] and compound (A) especially $[15,23]$ these changes relate to a shift of the $\pi-\pi$ stacked molecules along the long molecular axis towards the shorter center-to-center distance. As the solidstate absorption of compound (B) shows very similar shape even as-cast with no effect of annealing, we can conclude that an optimal donor phase arrangement is formed immediately during casting, improving thus a phase separation observed by AFM.

In summary we fully associate PCE decrease of the PEDOT:PSS containing (A) DPP $(\mathrm{TBFu})_{2}: \mathrm{PC}_{60} \mathrm{BM}$ devices with the degradation of the PEDOT:PSS/BHJ interface when annealing at $T>110^{\circ} \mathrm{C}$ is applied. On the other hand at temperatures $T>160^{\circ} \mathrm{C} \mathrm{BHJ}$ morphology degradation is the main issue. However material B possesses high crystallinity even at as-cast layers; PEDOT:PSS based devices have shown PCE augmentation up to $160^{\circ} \mathrm{C}$ and morphology degradation was observed only at $170^{\circ} \mathrm{C}$. Therefore it is correct to suppose that the PEDOT:PSS/BHJ interface is more thermally stable in case of the material (B). 


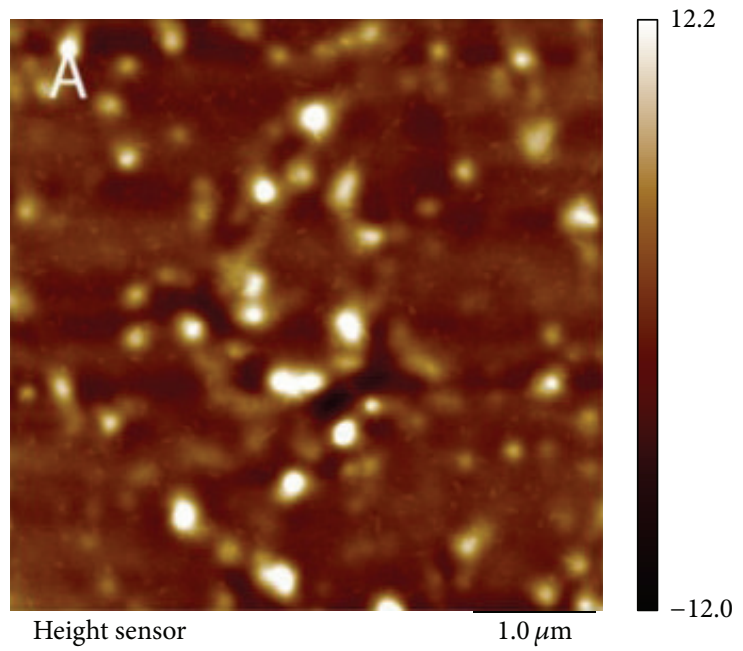

(a)

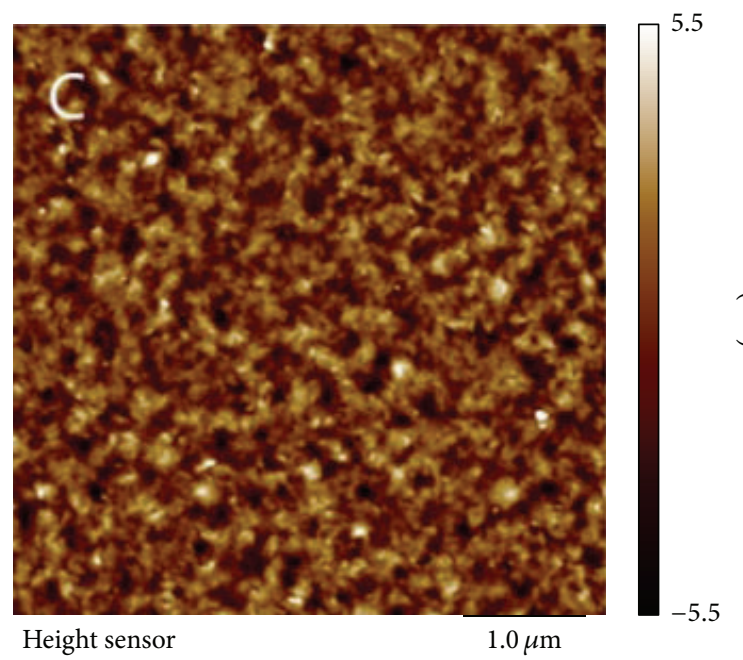

(c)

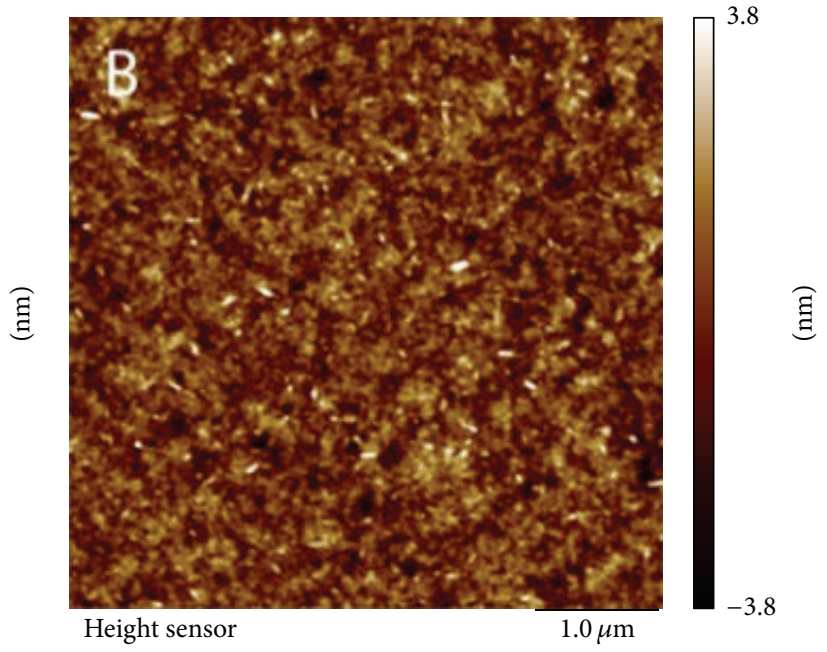

(b)

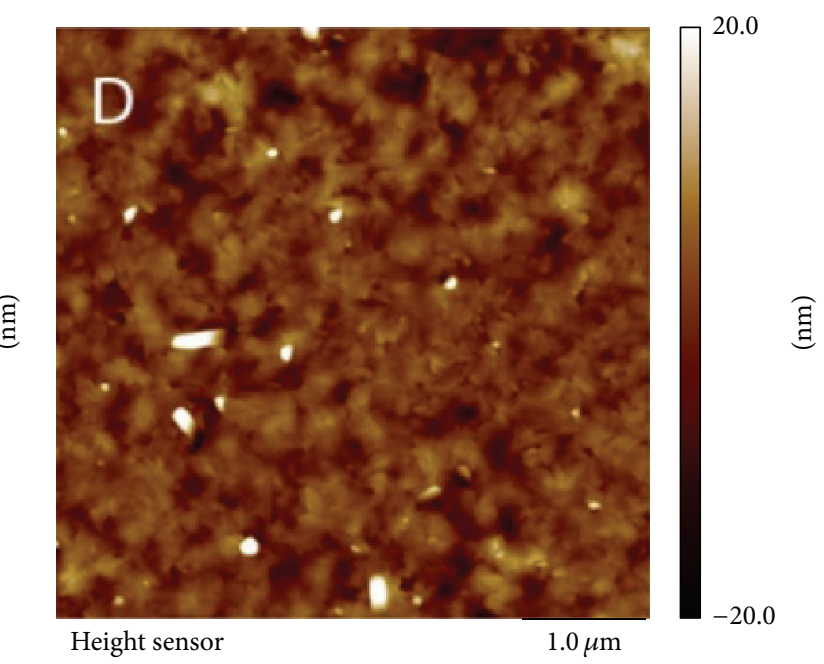

(d)

FIGURE 4: AFM images of the ethyl-hexyl alkylated (compound (A)) DPP(TBFu) $)_{2}: \mathrm{CC}_{60} \mathrm{BM}$ blend: as-cast $(\mathrm{A})$ and annealed at $110^{\circ} \mathrm{C}(\mathrm{B}), 140^{\circ} \mathrm{C}$ (C), and $160^{\circ} \mathrm{C}(\mathrm{D})$.

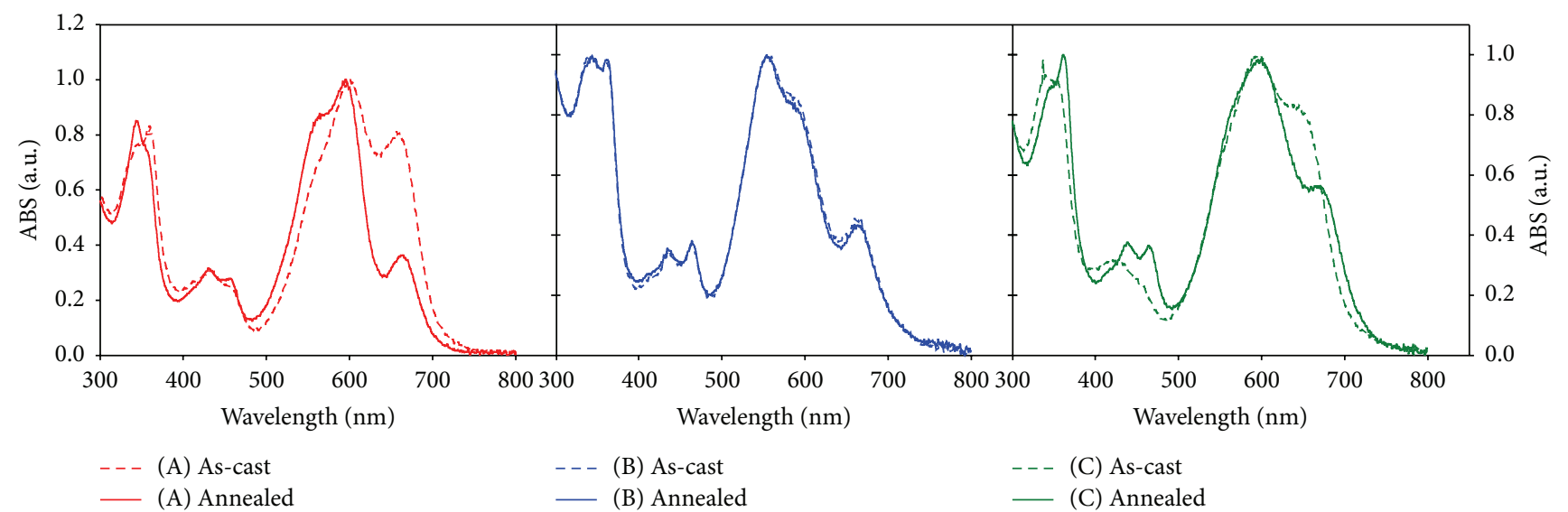

FIGURE 5: Normalized UV-Vis absorption spectra of the as-cast (dashed lines) and annealed at $140^{\circ} \mathrm{C}$ (solid lines) DPP:PC 60 BM blend layers. 


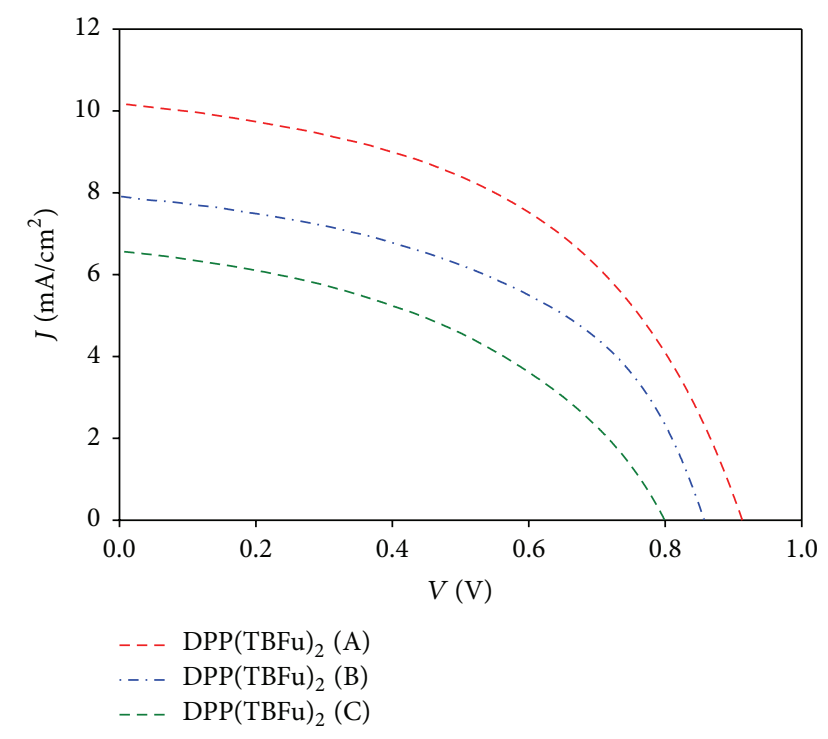

Figure 6: $J-V$ curves of the gradually annealed (at highest PCE) solar cells with $\mathrm{MoO}_{3}$ as an anode material.

As a result of the annealing and anode contact stability study, using $\mathrm{DPP}(\mathrm{TBFu})_{2}: \mathrm{PC}_{60} \mathrm{BM}$ we attained efficiencies $(\mathrm{PCE}=4.52 \%)$, with the values of $\mathrm{FF}, V_{\mathrm{oc}}$, and $J_{\mathrm{sc}}$ almost identical with the ones containing $\mathrm{PC}_{70} \mathrm{BM}$, described in original report [14]. New materials used in the present research possessed lower PCE values, even though material (B) shows a moderate PCE above $3.2 \%$. We see the main reason of $\mathrm{PCE}$ decrease when going from $\mathrm{A}$ to $\mathrm{B}$ in the lower $V_{\mathrm{oc}}$, that is, the trend on the contrary to the expectations coming from HOMO energies of isolated (A) and (B) derivatives, obtained from CV (Table 1). The decrease of $J_{s c}$ is considered as a consequence of the higher rate of charge recombination in the CT state of B. These effects will be further studied on an enlarged set of DPP donors. Final $J-V$ curves of the considered materials at the best annealing conditions are depicted in Figure 6. It has to be noted that good reproducibility was observed in case of all materials used. Statistics was done on 12 electrodes for each configuration and $80 \%$ of the electrodes were possessing PCE in a range of $\pm 0.2 \%$ when PEDOT:PSS was used as an anode material. In case $\mathrm{MoO}_{3}$ cathode reproducibility was even better $90 \%$ of devices have shown PCE deviation of $\pm 0.2 \%$.

3.3. Thermal Stability of Donor Materials. It is known that DPP derivatives, especially poorly soluble pigments, usually possess exceptional thermal stability $[41,42]$. TGA measurements in air have shown temperatures $356.47^{\circ} \mathrm{C}, 317.08^{\circ} \mathrm{C}$, and $300.55^{\circ} \mathrm{C}$ for samples (A), (B), and (C), respectively. Thus the main issue of the thermal degradation was expected to be the bulk-heterojunction morphology and contact/BHJ interfaces. Thermal degradation of the considered materials was carried out at $80^{\circ} \mathrm{C}$ and $110^{\circ} \mathrm{C}$ on both PEDOT:PSS and $\mathrm{MoO}_{3}$ based devices for 60 hours with several intermediate device characterizations to monitor the dynamics of the processes ongoing during the thermal annealing. Devices based on the above mentioned materials are showing exceptional stability at $80^{\circ} \mathrm{C}$ possessing no notable PCE losses after 60 hours of annealing in ambient atmosphere. However at $110^{\circ} \mathrm{C}$ after 24 hours degradation was observed, which is associated with devices decapsulation. As it was mentioned morphology of the bulk-heterojunction degrades at temperatures above $150^{\circ} \mathrm{C}$ for the materials (A) and (C). Material (B) was found to be the most stable regarding the $\mathrm{BHJ}$ morphology thermal stability; PCE decrease was observed at temperatures above $170^{\circ} \mathrm{C}$

\section{Conclusion}

One of the main achievements of the present paper is the study of the $\mathrm{MoO}_{3}$ anode contact advantages in case of the OSCs based on $\mathrm{DPP}(\mathrm{TBFU})_{2}$, where more thermally stable interface of active layer and anode contact allows using higher annealing temperatures resulting in higher efficiencies in comparison with PEDOT:PSS. It has also been shown that the gradual annealing is more advantageous and results in slightly higher PCE of the considered devices. As a result PCE of organic photovoltaics based on $\mathrm{DPP}(\mathrm{TBFu})_{2}: \mathrm{PC}_{60} \mathrm{BM} \mathrm{BHJ}$ is approaching the one based on $\mathrm{DPP}(\mathrm{TBFu})_{2}: \mathrm{PC}_{70} \mathrm{BM}$ and exceeding previously reported PCE values for $\mathrm{DPP}(\mathrm{TBFu})_{2}: \mathrm{PC}_{60} \mathrm{BM}$. Although PCE of the reference ethyl-hexyl alkylated $\mathrm{DPP}(\mathrm{TBFu})_{2}$ was not exceeded by the materials with electrophilic side chains, the acceptable values of the efficiencies were obtained, which along with higher reaction yields in the case of alkyl esters make considered materials relatively prospective. It is also worth mentioning that the modification of $\mathrm{DPP}(\mathrm{TBFu})_{2}$ with ethyl-hexyl acetate caused maximum values of $V_{\mathrm{oc}}$ and $J_{\mathrm{sc}}$ even without annealing, which can be identify ascast appropriate $\mathrm{BHJ}$ morphology as well as higher thermal morphology stability.

\section{Conflict of Interests}

The authors declare that there is no conflict of interests regarding the publication of this paper.

\section{Acknowledgments}

This work was supported by grant agency of the Czech Republic via Project no. 15-05095S; research infrastructure was supported by Projects MŠMT nos. LO1211 and LO1409. Dr. Jan David, Dr. Tomáš Mikysek, and Dr. Filip Bureš are gratefully acknowledged for the TGA measurements, electrochemical measurements, and synthesis and analytics consulting, respectively.

\section{References}

[1] C.-C. Chen, W.-H. Chang, K. Yoshimura et al., "An efficient triple-junction polymer solar cell having a power conversion efficiency exceeding 11\%," Advanced Materials, vol. 26, no. 32, pp. 5670-5677, 2014. 
[2] M. A. Green, K. Emery, D. L. King, Y. Hishikawa, and W. Warta, "Solar cell efficiency tables (version 29)," Progress in Photovoltaics, vol. 15, no. 1, pp. 35-40, 2007.

[3] C. Lungenschmied, G. Dennler, H. Neugebauer et al., "Flexible, long-lived, large-area, organic solar cells," Solar Energy Materials and Solar Cells, vol. 91, no. 5, pp. 379-384, 2007.

[4] Q. Zhang, B. Kan, F. Liu et al., "Small-molecule solar cells with efficiency over 9\%," Nature Photonics, vol. 9, pp. 35-41, 2015.

[5] Y. Liu, C.-C. Chen, Z. Hong et al., "Solution-processed smallmolecule solar cells: breaking the $10 \%$ power conversion efficiency," Scientific Reports, vol. 3, article 3356, pp. 1-8, 2013.

[6] H. K. H. Lee, Z. Li, I. Constantinou, F. So, S. W. Tsang, and S. K. So, "Batch-to-batch variation of polymeric photovoltaic materials: its origin and impacts on charge carrier transport and device performances," Advanced Energy Materials, vol. 4, no. 16, Article ID 1470084, 2014.

[7] Z. Huang, E. C. Fregoso, S. Dimitrov et al., "Optimisation of diketopyrrolopyrrole:fullerene solar cell performance through control of polymer molecular weight and thermal annealing," Journal of Materials Chemistry A, vol. 2, no. 45, pp. 19282-19289, 2014.

[8] H. Bronstein, E. Collado-Fregoso, A. Hadipour et al., "Thieno[3, $2-b]$ thiophene-diketopyrrolopyrrole containing polymers for inverted solar cells devices with high short circuit currents," Advanced Functional Materials, vol. 23, no. 45, pp. 5647-5654, 2013.

[9] W. Li, W. S. C. Roelofs, M. M. Wienk, and R. A. J. Janssen, "Enhancing the photocurrent in diketopyrrolopyrrole-based polymer solar cells via energy level control," Journal of the American Chemical Society, vol. 134, no. 33, pp. 13787-13795, 2012.

[10] I. Meager, R. S. Ashraf, S. Mollinger et al., "Photocurrent enhancement from diketopyrrolopyrrole polymer solar cells through alkyl-chain branching point manipulation," Journal of the American Chemical Society, vol. 135, no. 31, pp. 11537-11540, 2013.

[11] S. Loser, C. J. Bruns, H. Miyauchi et al., "A naphthodithiophenediketopyrrolopyrrole donor molecule for efficient solutionprocessed solar cells," Journal of the American Chemical Society, vol. 133, no. 21, pp. 8142-8145, 2011.

[12] B. Walker, J. Liu, C. Kim et al., "Optimization of energy levels by molecular design: evaluation of bis-diketopyrrolopyrrole molecular donor materials for bulk heterojunction solar cells," Energy and Environmental Science, vol. 6, no. 3, pp. 952-962, 2013.

[13] W. Li, M. Kelchtermans, M. M. Wienk, and R. A. J. Janssen, "Effect of structure on the solubility and photovoltaic properties of bis-diketopyrrolopyrrole molecules," Journal of Materials Chemistry A, vol. 1, no. 47, pp. 15150-15157, 2013.

[14] B. Walker, A. B. Tamayo, X.-D. Dang et al., "Nanoscale phase separation and high photovoltaic efficiency in solutionprocessed, small-molecule bulk heterojunction solar cells," Advanced Functional Materials, vol. 19, no. 19, pp. 3063-3069, 2009.

[15] J. Liu, B. Walker, A. Tamayo, Y. Zhang, and T.-Q. Nguyen, "Effects of heteroatom substitutions on the crystal structure, film formation, and optoelectronic properties of diketopyrrolopyrrole-based materials," Advanced Functional Materials, vol. 23, no. 1, pp. 47-56, 2013.

[16] Y. Zhang, X.-D. Dang, C. Kim, and T.-Q. Nguyen, "Effect of charge recombination on the fill factor of small molecule bulk heterojunction solar cells," Advanced Energy Materials, vol. 1, no. 4, pp. 610-617, 2011.

[17] K. Sun, Z. Xiao, E. Hanssen et al., "The role of solvent vapor annealing in highly efficient air-processed small molecule solar cells," Journal of Materials Chemistry A, vol. 2, no. 24, pp. 9048 9054, 2014.

[18] H. Bürckstümmer, E. V. Tulyakova, M. Deppisch et al., "Efficient solution-processed bulk heterojunction solar cells by antiparallel supramolecular arrangement of dipolar donor-acceptor dyes," Angewandte Chemie-International Edition, vol. 50, no. 49, pp. 11628-11632, 2011.

[19] Š. Frebort, M. Vala, S. Luňák Jr. et al., "Diphenylamine endcapped diketopyrrolopyrroles with phenylene-vinylene conjugation extension," Tetrahedron Letters, vol. 55, no. 17, pp. 28292834, 2014.

[20] E. Ripaud, D. Demeter, T. Rousseau et al., "Structure-properties relationships in conjugated molecules based on diketopyrrolopyrrole for organic photovoltaics," Dyes and Pigments, vol. 95, no. 1, pp. 126-133, 2012.

[21] D. Fernández, A. Viterisi, J. W. Ryan et al., "Small molecule BHJ solar cells based on DPP(TBFu $)_{2}$ and diphenylmethanofullerenes (DPM): linking morphology, transport, recombination and crystallinity," Nanoscale, vol. 6, no. 11, pp. 5871-5878, 2014.

[22] W. Cambarau, A. Viterisi, J. W. Ryan, and E. Palomares, "Small molecule-based tandem solar cells with solution-processed and vacuum-processed photoactive layers," Chemical Communications, vol. 50, no. 40, pp. 5349-5351, 2014.

[23] J. Liu, Y. Zhang, H. Phan et al., "Effects of stereoisomerism on the crystallization behavior and optoelectrical properties of conjugated molecules," Advanced Materials, vol. 25, no. 27, pp. 3645-3650, 2013.

[24] A. Viterisi, F. Gispert-Guirado, J. W. Ryan, and E. Palomares, "Formation of highly crystalline and texturized donor domains in $\mathrm{DPP}(\mathrm{TBFu})_{2}: \mathrm{PC}_{71} \mathrm{BM} \mathrm{SM}-\mathrm{BHJ}$ devices via solvent vapour annealing: implications for device function," Journal of Materials Chemistry, vol. 22, no. 30, pp. 15175-15182, 2012.

[25] Z. Li, X. Zhang, Y. Zhang et al., "Hole transport in diketopyrrolopyrrole (DPP) small molecules: a joint theoretical and experimental study," The Journal of Physical Chemistry C, vol. 117, no. 13, pp. 6730-6740, 2013.

[26] V. Shrotriya, G. Li, Y. Yao, C.-W. Chu, and Y. Yang, "Transition metal oxides as the buffer layer for polymer photovoltaic cells," Applied Physics Letters, vol. 88, no. 7, Article ID 073508, 2006.

[27] J. Subbiah, D. Y. Kim, M. Hartel, and F. So, " $\mathrm{MoO}_{3} / \operatorname{poly}(9,9-$ dioctylfluorene-co-N-[4-(3-methylpropyl)]-diphenylamine) double-interlayer effect on polymer solar cells," Applied Physics Letters, vol. 96, no. 6, Article ID 063303, 2010.

[28] J. W. Ryan, T. Kirchartz, A. Viterisi, J. Nelson, and E. Palomares, "Understanding the effect of donor layer thickness and a $\mathrm{MoO}_{3}$ hole transport layer on the open-circuit voltage in squaraine/ $\mathrm{C}_{60}$ bilayer solar cells," Journal of Physical Chemistry C, vol. 117, no. 39, pp. 19866-19874, 2013.

[29] M. Grzybowski, E. Glodkowska-Mrowka, T. Stoklosa, and D. T. Gryko, "Bright, color-tunable fluorescent dyes based on $\pi$ expanded diketopyrrolopyrroles," Organic Letters, vol. 14, no. 11, pp. 2670-2673, 2012.

[30] I. Kratochvílová, A. Kovalenko, F. Fendrych, V. Petráková, S. Záli, and M. Nesládek, “Tuning of nanodiamond particles' optical properties by structural defects and surface modifications: DFT modelling," Journal of Materials Chemistry, vol. 21, no. 45, pp. 18248-18255, 2011. 
[31] A. A. Isse and A. Gennaro, "Absolute potential of the standard hydrogen electrode and the problem of interconversion of potentials in different solvents," Journal of Physical Chemistry B, vol. 114, no. 23, pp. 7894-7899, 2010.

[32] S. Luňák Jr., M. Vala, J. Vyňuchal et al., "Absorption and fluorescence of soluble polar diketo-pyrrolo-pyrroles," Dyes and Pigments, vol. 91, no. 3, pp. 269-278, 2011.

[33] Š. Frebort, Z. Eliáš, A. Lyčka et al., "O- and N-alkylated diketopyrrolopyrrole derivatives," Tetrahedron Letters, vol. 52, no. 44, pp. 5769-5773, 2011.

[34] R. A. J. Janssen and J. Nelson, "Factors limiting device efficiency in organic photovoltaics," Advanced Materials, vol. 25, no. 13, pp. 1847-1858, 2013.

[35] B. Friedel, P. E. Keivanidis, T. J. K. Brenner et al., "Effects of layer thickness and annealing of PEDOT:PSS layers in organic photodetectors," Macromolecules, vol. 42, no. 17, pp. 6741-6747, 2009.

[36] M. Hokazono, H. Anno, and N. Toshima, "Thermoelectric properties and thermal stability of PEDOT:PSS films on a polyimide substrate and application in flexible energy conversion devices," Journal of Electronic Materials, vol. 43, no. 6, pp. 21962201, 2014.

[37] M. Kirkus, L. Wang, S. Mothy et al., "Optical properties of oligothiophene substituted diketopyrrolopyrrole derivatives in the solid phase: joint J- and H-type aggregation," Journal of Physical Chemistry A, vol. 116, no. 30, pp. 7927-7936, 2012.

[38] F. C. Spano, "The spectral signatures of frenkel polarons in $\mathrm{H}-$ and J-aggregates," Accounts of Chemical Research, vol. 43, no. 3, pp. 429-439, 2010.

[39] X. Guo, N. Zhou, S. J. Lou et al., "Polymer solar cells with enhanced fill factors," Nature Photonics, vol. 7, no. 10, pp. 825833, 2013.

[40] W. Shin, T. Yasuda, G. Watanabe, Y. S. Yang, and C. Adachi, "Self-organizing mesomorphic diketopyrrolopyrrole derivatives for efficient solution-processed organic solar cells," Chemistry of Materials, vol. 25, no. 12, pp. 2549-2556, 2013.

[41] S.-H. Choi, G.-H. Kil, N.-R. Kim, Ch. Yoon, J.-P. Kim, and J.H. Choi, "Preparation of thermally stable red dyes derived from diketo-pyrrolo-pyrrole pigment for LCD color filter," Molecular Crystals and Liquid Crystals, vol. 550, no. 1, pp. 76-82, 2011.

[42] M. Kaur and D. H. Choi, "Diketopyrrolopyrrole: brilliant red pigment dye-based fluorescent probes and their applications," Chemical Society Reviews, vol. 44, no. 1, pp. 58-77, 2015. 

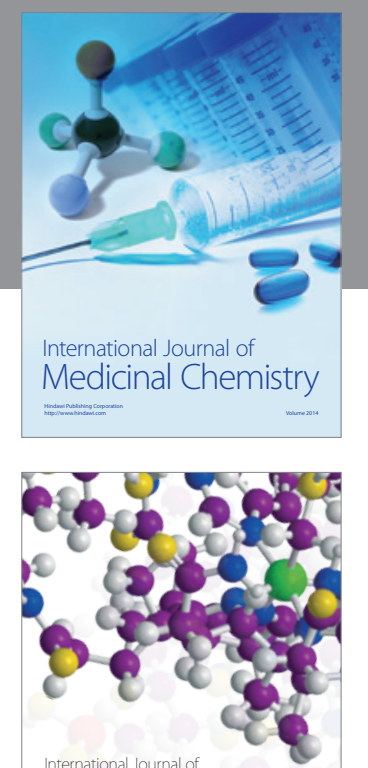

\section{Carbohydrate} Chemistry

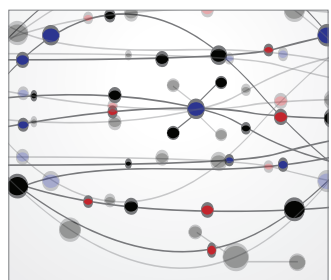

The Scientific World Journal
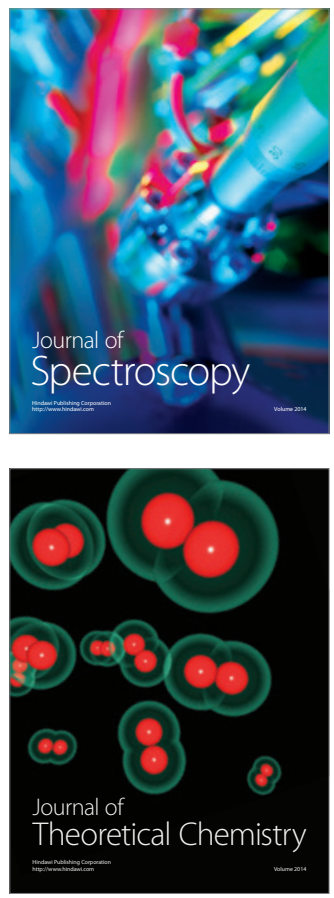
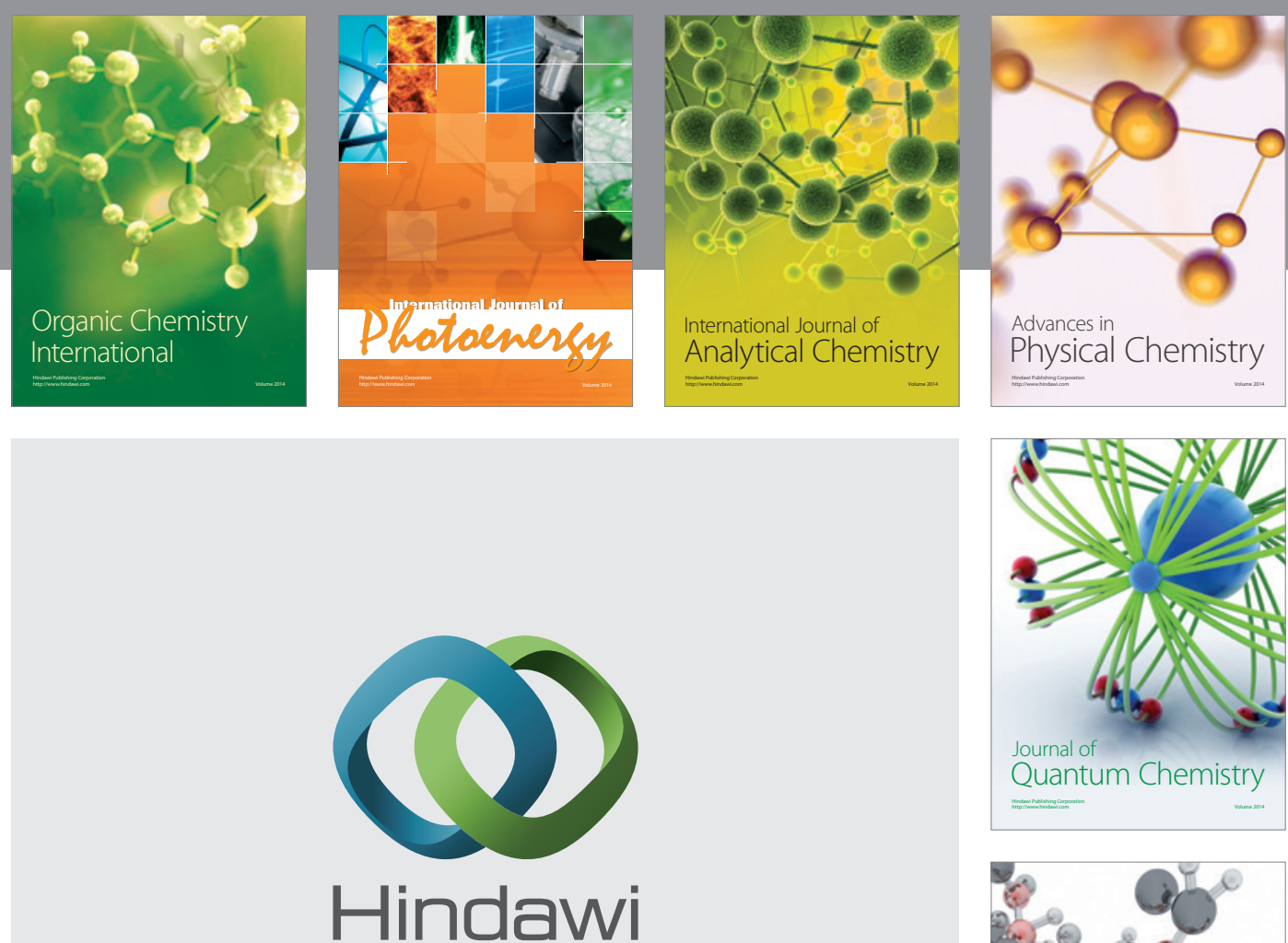

Submit your manuscripts at

http://www.hindawi.com

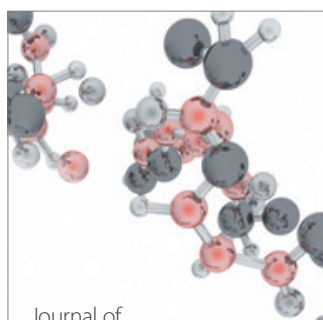

Analytical Methods

in Chemistry

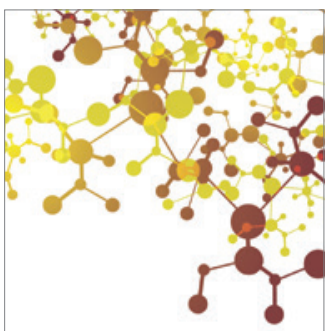

Journal of

Applied Chemistry

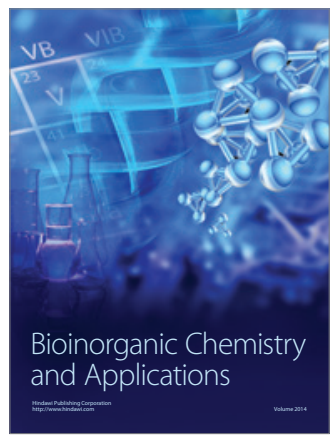

Inorganic Chemistry
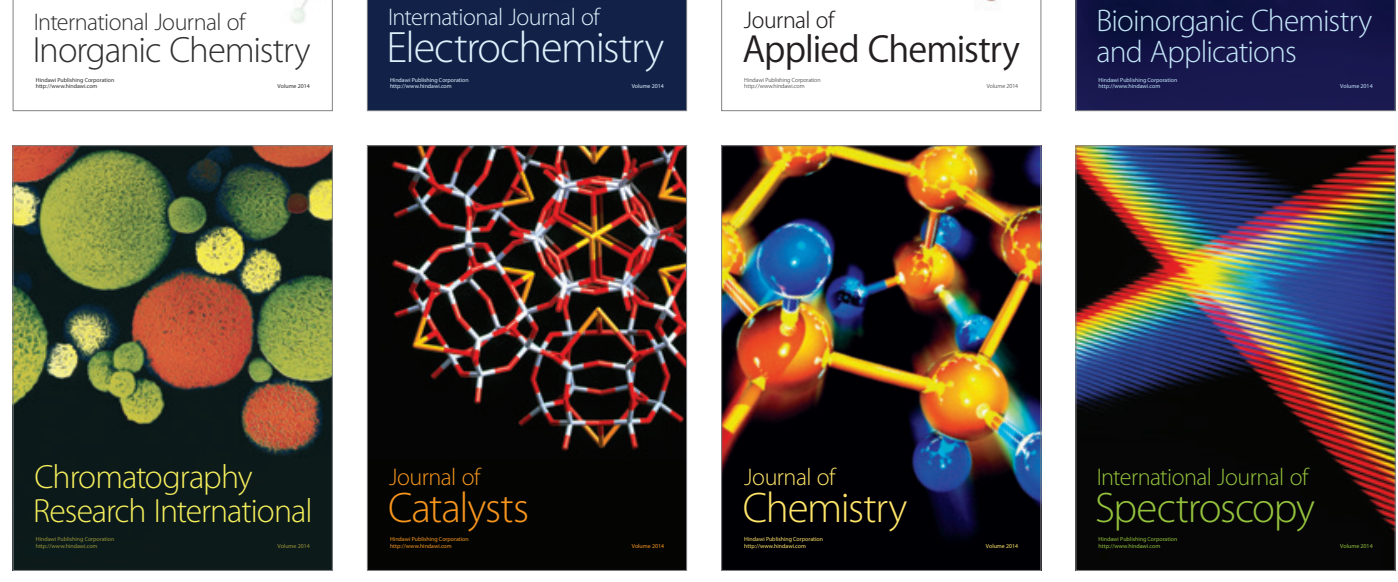